\title{
Densely calcified aortic arch and right coronary artery
}

\author{
Zeki Doğan (D), Gökhan Bektaşoğlu(D), Enes Elvin Gül(D) \\ Department of Cardiology, Istanbul Medicine Hospital, Istanbul, Turkey
}

Received: February 19, 2018 Accepted: April 21, 2018 Published online: April 24, 2019

An 80-year-old woman was admitted to the cardiology unit due to ongoing chest pain and shortness of breath. Twelve-lead electrocardiography showed unremarkable findings. As she had ongoing angina and high risk due to her age and history of diabetes, coronary angiography was planned. Coronary
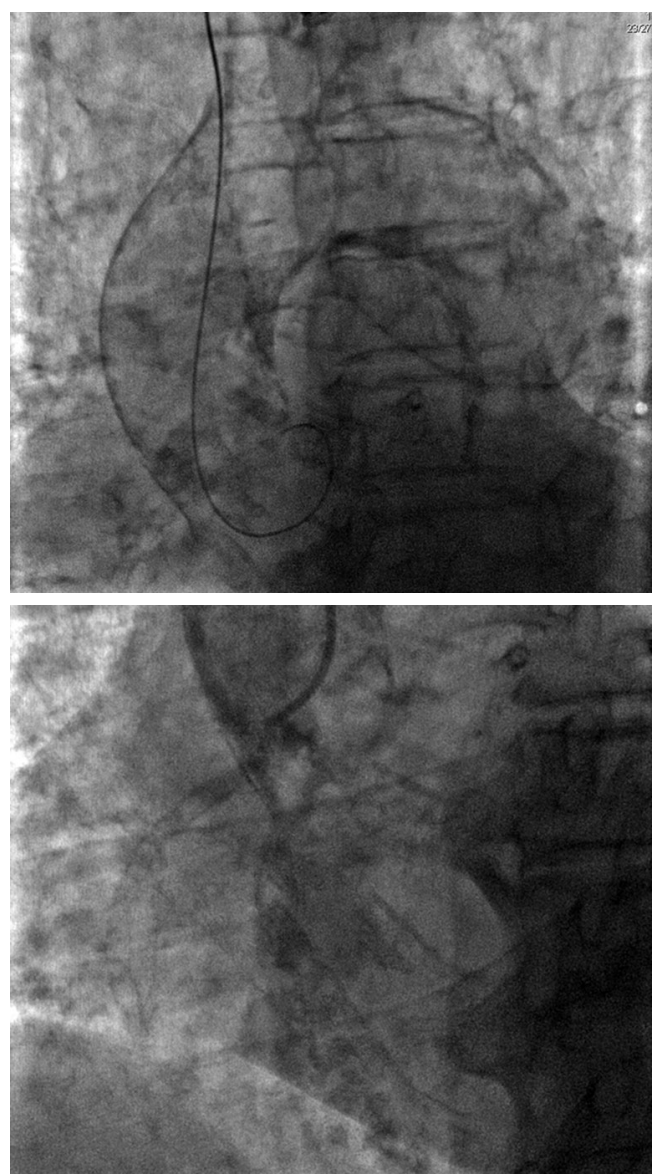

Figure 1. Fluoroscopic images during coronary angiographic examination showing a very clear dense calcification of aortic arch and right coronary artery. angiography revealed a very dense and calcified aortic arch and right coronary artery (RCA) (Figure 1, Video 1). However, we were unable to visualize the RCA, due to severe calcification obstructing the ostium of the artery. There were also severe lesions in the left coronary system. The decision was made in favor of coronary artery bypass grafting; however both the patient and her family members refused this decision and opted to carry on medical treatment. The patient was discharged on the second day of her admission.

This case demonstrates a very impressive image of severe calcification of the aortic arch and right coronary artery.

\section{Declaration of conflicting interests}

The authors declared no conflicts of interest with respect to the authorship and/or publication of this article.

\section{Funding}

The authors received no financial support for the research and/or authorship of this article.
Corresponding author: Enes Elvin Gül, MD. İstanbul Medicine Hastanesi Kardiyoloji Bölümü, 34203 Bağcclar, İstanbul, Turkey.

Tel: +90 212 - 4440205 e-mail: elvin_salamov@yahoo.com

\section{Citation:}

Doğan Z, Bektașoğlu G, Gül EE. Densely calcified aortic arch and right coronary artery. Cardiovasc Surg Int 2018;5(2):36. 